\title{
Proteinuria and its relation to cardiovascular disease
}

This article was published in the following Dove Press journal: International Journal of Nephrology and Renovascular Disease 2I December 2013

Number of times this article has been viewed

\section{Gemma Currie Christian Delles}

University of Glasgow, Institute of Cardiovascular and Medical Sciences, Glasgow, UK
Correspondence: Gemma Currie Institute of Cardiovascular and Medical Sciences,

BHF Glasgow Cardiovascular Research Centre, University of Glasgow, 126 University Place, Glasgow, GI 2 8TA, UK Tel $+44|4| 3305189$ Fax +44 |4| $33027 \mid$ I

Email gemma.currie@glasgow.ac.uk
Abstract: Chronic kidney disease (CKD) and its associated morbidity pose a worldwide health problem. As well as risk of endstage renal disease requiring renal replacement therapy, cardiovascular disease is the leading cause of premature death among the CKD population. Proteinuria is a marker of renal injury that can often be detected earlier than any tangible decline in glomerular filtration rate. As well as being a risk marker for decline in renal function, proteinuria is now widely accepted as an independent risk factor for cardiovascular morbidity and mortality. This review will address the prognostic implications of proteinuria in the general population as well as other specific disease states including diabetes, hypertension and heart failure. A variety of pathophysiological mechanisms that may underlie the relationship between renal and cardiovascular disease have been proposed, including insulin resistance, inflammation, and endothelial dysfunction. As proteinuria has evolved into a therapeutic target for cardiovascular risk reduction in the clinical setting we will also review therapeutic strategies that should be considered for patients with persistent proteinuria.

Keywords: proteinuria, albuminuria, microalbuminuria, cardiovascular risk

\section{Introduction}

The association between chronic kidney disease (CKD) and cardiovascular disease has long been recognised and current guidelines recommend that patients with CKD be considered to be at particularly high cardiovascular risk. ${ }^{1}$ Although often transient and benign, the persistent presence of protein or albumin in the urine has marked clinical significance as an early indicator of underlying renal pathology, preceding tangible decline in renal filtration function. In addition to its role as a marker for CKD risk, it is now widely accepted that proteinuria is an independent predictor of cardiovascular morbidity and mortality across divergent populations. ${ }^{2}$ This review will address the role of proteinuria as a cardiovascular risk marker, the mechanisms and risk factors proposed to underlie this relationship and current pharmacological and non-pharmacological treatment strategies for individuals with proteinuria. Due to heterogeneity of detection methods used in published studies, this article will consider classifications including microalbuminuria, albuminuria, and proteinuria.

\section{Background}

National Health and Nutrition Examination Survey study (NHANES) data demonstrated that proteinuria is present in $4 \%$ of men and $2 \%$ of women between 45 and 74 years of age in the general population ${ }^{3}$ and up to $26 \%$ of patients with estimated glomerular filtration rate $(\mathrm{eGFR})<30 \mathrm{~mL} / \mathrm{minute} / 1.73 \mathrm{~m} \cdot{ }^{2,4}$ Data from the Framingham Heart Study 
found a higher prevalence among older people, with dipstick proteinuria detected in $17.4 \%$ of men and $12.9 \%$ of women at baseline. ${ }^{5}$ In treated hypertensive patients, the reported prevalence of proteinuria varies between 4 and $15 \%{ }^{6,7}$

Classifications of proteinuria according to the diagnostic test used are defined in Table 1. Although the accepted gold standard for measuring proteinuria is 24 hour urinary protein excretion, this method can be cumbersome for patients and frequent error is encountered due to improper collection. A spot urine dipstick sample is often considered to be a more practical alternative. This method has high specificity of $97 \%$ or greater but poor sensitivity as false negatives can be encountered when urine samples are particularly dilute. ${ }^{8}$ The Kidney Disease Outcomes Quality Initiative (KDOQI) guidelines recommend initial screening of at risk individuals with a standard urine dipstick. Those with a positive test should then proceed to a confirmatory quantitative test such as spot urine protein:creatinine (PCR) or albumin:creatinine ratio (ACR), both of which have been shown to correlate well with 24 hour urine protein quantification. ${ }^{9}$ Spot urine tests are subject to a significant degree of variability depending on multiple individual factors, and therefore repeating these tests is essential to obtain confirmation of initial abnormal results. ${ }^{9}$

\section{CKD and cardiovascular risk}

The presence of CKD is a powerful predictor of adverse clinical outcomes. ${ }^{10,11}$ Cardiovascular disease is by far the most common cause of death in dialysis-dependent and renal transplant patients. Only a small minority of the CKD population progress to endstage renal disease requiring renal replacement therapy (RRT), with death prior to RRT being far more common. ${ }^{11}$ A 2010 meta-analysis with data for over 1 million subjects reported that stage $3 \mathrm{CKD}$ (eGFR $<60 \mathrm{~mL} / \mathrm{minute} / 1.73 \mathrm{~m}^{2}$ ) was associated with both cardiovascular and all-cause mortality. ${ }^{12}$ In a systematic review of associations between non-dialysis-dependent CKD and mortality, Tonelli et al reported that the absolute risk of death increased exponentially with declining renal function. ${ }^{13}$ Even the earliest, clinically silent stages of CKD have been associated with major cardiovascular disease. ${ }^{14}$ In addition to reduced eGFR, ACR and dipstick positive proteinuria have also been associated with graded cardiovascular and all-cause mortality, acting as risk multipliers across all levels of renal function. ${ }^{15,16}$ In a large Canadian study, Hemmelgarn et al found that heavy proteinuria independently increased risk of death, myocardial infarction (MI) and progression of CKD in particular patient groups. ${ }^{17}$

\section{Proteinuria and clinical cardiovascular outcomes}

\section{General population}

Evidence now suggests that proteinuria has implications for all-cause mortality and cardiovascular outcomes at a general population level, not only in individuals with CKD. Population based cohort studies have shown that multivariable relative risks of cardiovascular disease mortality for proteinuria range from 1.2-2.9.3,18,19 The Prevention of Renal and Vascular Endstage Disease (PREVEND) study included over 40,000 individuals and found that a 2-fold increase in ACR equated to close to a $30 \%$ increase in risk for cardiovascular mortality. ${ }^{20}$ Moreover, this relationship is constant across distinct ethnic groups ${ }^{1,21-23}$ and in elderly populations. ${ }^{5,24}$ In terms of cardiovascular morbidity, dipstick positive proteinuria and ACR have emerged as predictors of cardiovascular diseases including ischemic heart disease, stroke, and hypertension in the general population, with some sources suggesting that proteinuria is a stronger predictor of outcome than traditional risk factors such as blood pressure and cholesterol. 7,22,25,26 Indeed, the Heart Outcomes Prevention Evaluation (HOPE) study found that proteinuria was associated with adverse outcome independently of

Table I Classification of proteinuria

\begin{tabular}{|c|c|c|c|c|}
\hline Diagnostic test & Normal albuminuria & Microalbuminuria & Albuminuria & Proteinuria \\
\hline $\begin{array}{l}24 \text { hour urine albumin } \\
\text { collection }\end{array}$ & $<30 \mathrm{mg} / 24$ hours & $30-300 \mathrm{mg} / 24$ hours & $>300 \mathrm{mg} / 24$ hours & $\begin{array}{l}>300 \mathrm{mg} / \\
24 \text { hours }\end{array}$ \\
\hline Spot urine dipstick & $<30 \mathrm{mg} / \mathrm{dL}$ & $N / A$ & $>30 \mathrm{mg} / \mathrm{dL}$ & $>30 \mathrm{mg} / \mathrm{dL}$ \\
\hline Spot urine albumin & $<17$ mg/g (men) & $17-250$ mg/g (men) & $>250 \mathrm{mg} / \mathrm{g}(\mathrm{men})$ & N/A \\
\hline \multirow[t]{4}{*}{ to creatinine ratio } & $<25$ mg/g (women) & 25-355 mg/g (women) & $>355$ mg/g (women) & \\
\hline & $<2.5 \mathrm{mg} / \mathrm{mmol}$ (men) & $<35 \mathrm{mg} / \mathrm{mmol}$ & $>35 \mathrm{mg} / \mathrm{mmol}$ & \\
\hline & $<3.5 \mathrm{mg} / \mathrm{mmol}$ (women) & $30-300 \mathrm{ug} / \mathrm{mg}$ & $>300 \mathrm{ug} / \mathrm{mg}$ & \\
\hline & $<30 \mathrm{ug} / \mathrm{mg}$ & & & \\
\hline Spot urine protein & $<200 \mathrm{mg} / \mathrm{g}$ & $\mathrm{N} / \mathrm{A}$ & $\mathrm{N} / \mathrm{A}$ & $>200 \mathrm{mg} / \mathrm{g}$ \\
\hline to creatinine ratio & $<45 \mathrm{mg} / \mathrm{mmol}$ & & & $>45 \mathrm{mg} / \mathrm{mmol}$ \\
\hline
\end{tabular}

Abbreviation: N/A, not available. 
traditional cardiovascular risk factors. ${ }^{27}$ Furthermore, cardiovascular risk appears to be increased even at levels of urinary protein excretion that are not considered to be pathological $^{28}$ and in fact there is no distinct threshold level that confers increased cardiovascular risk; rather, increasing albuminuria is associated with a graded increase in risk. ${ }^{29,30}$ Proteinuria has also been associated with increased risk of atherosclerotic events affecting the peripheral vasculature. Patients with proteinuria have been shown to have increased risk of incident stroke. A 2010 meta-analysis of studies totaling 48,000 participants reported that the presence of microalbuminuria was associated with a future stroke risk $90 \%$ greater than that of normoalbuminuric individuals. The impact of microalbuminuria was greatest on ischemic stroke incidence in those with a prior history of cerebrovascular disease and found to be relatively modest within the diabetic population. ${ }^{31}$ A further meta-analysis of the relationship between proteinuria and stroke has suggested that risk rises with degree of urinary protein excretion. ${ }^{32}$

\section{Hypertension and ischemic heart disease}

In the hypertensive population, studies suggest that microalbuminuria confers a 4 times greater risk of subsequent ischemic heart disease than in normoalbuminuric individuals. ${ }^{33}$ This effect appears to be independent of conventional atherosclerotic risk factors. In addition, albuminuria has been associated with the presence of left ventricular hypertrophy in patients with hypertension and diabetes. ${ }^{29,34-36}$ It has also been demonstrated that in individuals with stable underlying coronary artery disease, proteinuria confers increased risks of all-cause and cardiovascular mortality, even at lower levels within the defined "normal range". ${ }^{37}$ This has also been shown in individuals who have recently suffered a coronary event. ${ }^{38,39}$ The Pravastatin or Atorvastatin Evaluation and Infection Therapy-Thrombolysis in Myocardial Infarction (PROVE IT-TIMI 22) study showed that macro- rather than microalbuminuria was a better predictor of mortality in this group. ${ }^{39}$

\section{Diabetes}

Since the mid-1980s, accumulating evidence has linked microalbuminuria with mortality in patients with diabetes, ${ }^{40-42}$ both those with reduced and normal eGFR. ${ }^{43,44}$ Data from a pooled analysis of cohort studies including more than 2,000 patients suggest that the overall odds ratio for all-cause mortality in type 2 diabetic patients with microalbuminuria is 2.4 (confidence interval [CI] 1.8-3.1). ${ }^{45}$ Similarly, data suggest that type 1 diabetic patients with albuminuria have nine times greater cardiovascular mortality than those who are normoalbuminuric. ${ }^{46}$ The strong association between proteinuria and cardiovascular morbidity and mortality in type 2 diabetes has also been well-documented, both in patients with and without nephropathy. ${ }^{47-49}$ Data from the World Health Organization (WHO) Multinational Study of Vascular Disease in Diabetics confirm the association between clinical proteinuria and ischemic heart disease in type 2 diabetes. ${ }^{50}$ However, the Bypass Angioplasty Revascularization Investigation 2 Diabetes study of type 2 diabetic patients with cardiovascular disease reported that only $33 \%$ of participants had clinically confirmed albuminuria, although this was found to be associated with left ventricular dysfunction and peripheral vascular disease..$^{51}$ The Strong Heart Study confirmed association between albuminuria and abnormal systolic and diastolic ventricular function in individuals with type 2 diabetes. ${ }^{52}$ These findings have been replicated in the Non-Insulin-Dependent Diabetes, Hypertension, Microalbuminuria or Proteinuria, Cardiovascular Events, and Ramipril (DIABHYCAR), Reduction of Endpoints in NIDDM with the Angiotensin II Antagonist Losartan (RENAAL) and Losartan Intervention for Endpoint Reduction (LIFE) studies. ${ }^{53-55}$

\section{Heart failure}

Chronic heart failure lies at the end of the spectrum of cardiovascular disease, with $32 \%$ of individuals admitted to hospital with a diagnosis of heart failure dying within 1-year. It is thought to affect around 14 million people in Europe and 4.8 million Americans. ${ }^{56}$ A 2005 study of 94 stable chronic heart failure patients with New York Heart Association (NYHA) functional class III to IV symptoms found that $32 \%$ had evidence of microalbuminuria. ${ }^{57}$ Similar findings have been published from follow up of 2,310 patients in the Candesartan in Heart Failure-Assessment of Reduction in Mortality and Morbidity (CHARM) study, with 30\% of patients having microalbuminuria and a further $11 \%$ with confirmed macroalbuminuria ${ }^{58}$ and these were echoed in the Aliskiren Observation of Heart Failure Treatment (ALOFT) study. ${ }^{59}$ Proteinuria is a well documented risk factor for heart failure ${ }^{57}$ but, in addition, appears to provide prognostic information. In the CHARM population, ACR was an independent predictor of mortality, conferring a 40\%-80\% increase in relative risk. It also predicted outcome when assessed as a continuous variable with each $100 \mathrm{mg} / \mathrm{mmol}$ increment conferring a $10 \%$ increase in mortality risk. The Prospective Randomized Enalapril Study Evaluating Regression of Ventricular Enlargement (PRESERVE) study 
found that dipstick positive proteinuria was an independent predictor of clinical outcome in heart failure patients irrespective of specific level of proteinuria. ${ }^{60}$ Microalbuminuria also conferred a $30 \%-70 \%$ increased risk of hospitalization for heart failure. ${ }^{58}$ Data from the ALOFT study suggested that albuminuria predicted greater left ventricular end diastolic dimension and a trend towards increased N-terminal prohormone of brain natriuretic peptide (NT-pro BNP) levels. ${ }^{59}$

\section{Surrogate cardiovascular risk markers}

A number of studies have demonstrated an independent association between proteinuria and other surrogate markers of cardiovascular disease. For example, data from the PREVEND study found microalbuminuria to be independently associated with electrocardiographic (ECG) indicators of myocardial ischemia. ${ }^{61}$ In addition, a number of cross sectional studies have linked microalbuminuria with carotid artery intima media thickness. ${ }^{62,63}$ The association between microalbuminuria and left ventricular hypertrophy (LVH) has been shown in a number of cohorts including the LIFE and Multi-Ethnic Study of Atherosclerosis (MESA) populations, where albuminuria was linked with both electrocardiogram (ECG) and magnetic resonance imaging (MRI) defined LVH. ${ }^{30,64}$ Microalbuminuria was also associated with increased coronary artery calcification scores in the MESA trial, ${ }^{64}$ and with carotid-femoral pulse wave velocity in Framingham data. ${ }^{65}$

\section{Mechanisms underlying cardiovascular consequences of proteinuria}

The Steno hypothesis suggested that urinary protein excretion not only reflects localized subclinical renal disease but also a more generalized vascular endothelial dysfunction. ${ }^{66}$ High-sensitivity troponin T (hs-TnT) as a marker of vascular micronecrosis has been found to independently predict transitions in albuminuria grade. ${ }^{67}$ Microalbuminuria is also accompanied by a fall in adiponectin levels and elevated C-reactive protein (CRP) ${ }^{68}$ and there appears to be a significant correlation between degree of proteinuria and CRP level. ${ }^{2}$ Evidence has also linked proteinuria with asymmetric dimethylarginine (ADMA), an inflammatory biomarker which causes endothelial dysfunction through inhibition of nitric oxide production. ${ }^{69}$ Circulating von Willebrand Factor (vWF) antigen is released in greater concentrations in response to endothelial cell damage. Levels of vWF have been shown to be higher in patients with microalbuminuria compared to control subject. ${ }^{70}$ Macrovascular endothelial dysfunction assessed by flow-mediated dilatation has been shown to be impaired in individuals with proteinuria. ${ }^{2}$ Vascular endothelial growth factor (VEGF) is another interesting potential mechanistic link between proteinuria and endothelial dysfunction. Use of VEGF-antagonists as angiogenesis inhibitors for the treatment of patients with cancers have been associated with increased incidence of proteinuria and hypertension, an effect which was reversed on withdrawal of therapy. ${ }^{71}$

As well as inflammation and endothelial dysfunction, thrombogenic factors have been implicated as potential mechanisms underlying the relationship between proteinuria and cardiovascular disease. In addition to $\mathrm{vWF}$, soluble vascular cell adhesion molecule, fibrinogen, and tissue plasminogen activator have been found to correlate with urinary albumin excretion. ${ }^{72}$ A variety of hemostatic abnormalities have been described in patients with diabetes ${ }^{73}$ and it has been suggested that high platelet adhesiveness and erythrocyte aggregation demonstrated in diabetic patients with proteinuria could indicate increased thrombosis risk. ${ }^{74}$

Both insulin resistance and proteinuria have been associated with atherogenesis. The Insulin Resistance Atherosclerosis Study involving 982 nondiabetic participants found that microalbuminuric subjects had lower insulin sensitivity and higher plasma insulin levels compared to normal albuminuric participants, leading the authors to propose that insulin resistance has a role to play in the increased cardiovascular risk conferred by proteinuria. ${ }^{75}$ Hyperinsulinemia has been shown to cause renal vasodilatation and increased glomerular filtration rate in rats, with some suggesting that this localized elevated pressure is involved in regulating urinary albumin excretion. ${ }^{75}$ As well as demonstrating association between insulin resistance and microalbuminuria, Bianchi et al noted that in patients with essential hypertension, microalbuminuria was associated with altered lipid profile and an abnormal circadian blood pressure pattern, thus forming part of a cluster with potential to modify cardiovascular risk in these individuals. ${ }^{76}$

\section{Risk factors for proteinuria}

Despite its evolving role as a major risk factor for cardiovascular disease, little is known about factors that determine the onset of proteinuria. The majority of studies demonstrating relationships between proteinuria and other major cardiovascular risk factors are cross-sectional and so inference regarding causality cannot be drawn. In one 10-year prospective cohort study of 157,377 healthy Korean adults who were free of proteinuria at baseline, fasting glucose and cholesterol levels, as well as body mass index and blood pressure were 
found to be independent predictors of incident proteinuria. Furthermore, cardiovascular risk increased in a progressive, dose-response manner, even at levels of protein excretion falling below currently accepted thresholds for cardiovascular disease prevention..$^{77}$ Data from the Baltimore Longitudinal Study of Ageing confirmed the association between albuminuria and blood pressure, but suggested that urine albumin excretion was more strongly associated with systolic blood pressure and pulse pressure, and this finding was statistically significant only in males. ${ }^{78}$ Certainly, links between abnormal lipid profiles and CKD are well documented in both diabetic and non-diabetic populations. ${ }^{79,80}$ Obesity has been associated with glomerular hyperfiltration and microalbuminuria in subjects with and without diabetes. ${ }^{77,81}$ A number of studies have linked body mass index with incident proteinuria but it has been suggested that perhaps body fat distribution is more significant as central body fat appears to confer greater risk in lean, overweight and clinically obese patients ${ }^{82}$ Risk of incident proteinuria appears to increase in parallel with the number of features of the metabolic syndrome elicited in individuals, regardless of age or sex. ${ }^{83}$

A cluster of cardiovascular risk factors has also been noted in hypertensive populations with microalbuminuria. In a study of normal albuminuric patients who were under 50 years old with essential hypertension followed up over 3 years, baseline microalbuminuria values and the slopes of systolic blood pressure and fasting glucose emerged as independent predictors of incident proteinuria. ${ }^{84}$ Evidence also links hyperinsulinemia with microalbuminuria, and the increase in baseline albumin excretion may reflect a degree of subclinical end-organ damage in values below the defined threshold for microalbuminuria. The Hypertension and Ambulatory Recording Venetia Study (HARVEST) study followed normal albuminuric hypertensive patients for 7 years and confirmed that 24 hour systolic blood pressure was a predictor of microalbuminuria, but also named age and female sex amongst implicated risk factors. ${ }^{85}$

The interrelationship between proteinuria and diabetes is well-documented. In a cross sectional study evaluating 24,000 type 2 diabetic patients, elevated albumin excretion was most prevalent in Asian and Hispanic patients. $\mathrm{HbA}_{1 \mathrm{c}}$, blood pressure, diabetes duration, smoking, and baseline renal function were all independent risk factors for miroalbuminuria. ${ }^{86}$ Surprisingly, body mass index was not a risk factor for incident proteinuria, perhaps because microalbuminuria was most prevalent in the Asian population, who had lower values. In cross-sectional data from the Randomized Olmesartan and Diabetes Microalbuminuria
Prevention (ROADMAP) study, the factors most strongly correlated with degree of albuminuria within the normal range were blood pressure, pulse pressure, $\mathrm{HbA}_{1 c}$, eGFR, and uric acid levels. In terms of categorical variables, higher albumin excretion was found in those with greater waist circumference, smokers, females and those who were treated with insulin..$^{81}$ Although such observational correlations do not infer causality, many of the factors linked to albumin excretion are potential targets for intervention when aiming to minimize overall cardiovascular risk.

\section{Pharmacological interventions}

Given that the presence of proteinuria is independently associated with increased risk of cardiovascular morbidity and mortality it has evolved into a therapeutic target for cardiovascular risk reduction. In the LIFE study, greater reductions in urinary albumin excretion were seen in subjects with the lowest cardiovascular event rate ${ }^{87}$ Similar findings have been published from the RENAAL study ${ }^{49}$ but results of other projects such as the Prevention of Renal and Vascular Endstage Disease Intervention Trial (PREVEND- IT) have been less convincing. ${ }^{88}$

Cardiovascular risk management in patients with proteinuria focuses on reduction or control of degree of proteinuria and modification of additional risk factors including blood pressure, diabetes, lipid profile, smoking, and obesity. Results of the Modification of Diet in Renal Disease study highlighted the importance of tight blood pressure control in patients with CKD and proteinuria ${ }^{89}$ as did the UK Prospective Diabetes Study (UKPDS) for those with diabetes. ${ }^{90}$ Current evidence-based guidelines highlight the importance of renin-angiotensin-aldosterone system (RAAS) inhibition (Figure 1) as the first line therapeutic strategy in terms of slowing progression of nephropathy and reducing proteinuria in these populations..$^{91,92}$ Many patients will require additional antihypertensive therapy which should be prescribed according to each individual's characteristics. These additional agents may not have specific antiproteinuric properties but lowering of blood pressure itself can have beneficial effects on protein excretion. ${ }^{89,90}$

\section{RAAS blocking agents}

The renoprotective benefits of angiotensin-converting enzyme inhibitors (ACE-inhibitors) and angiotensin receptor blockers in both diabetic and non-diabetic chronic kidney disease are well documented and out of the scope of this review. ${ }^{93-97}$ In a sub-analysis of the HOPE study, ramipril treatment resulted in significantly reduced cardiovascular risk in participants with renal impairment. This cardioprotective 


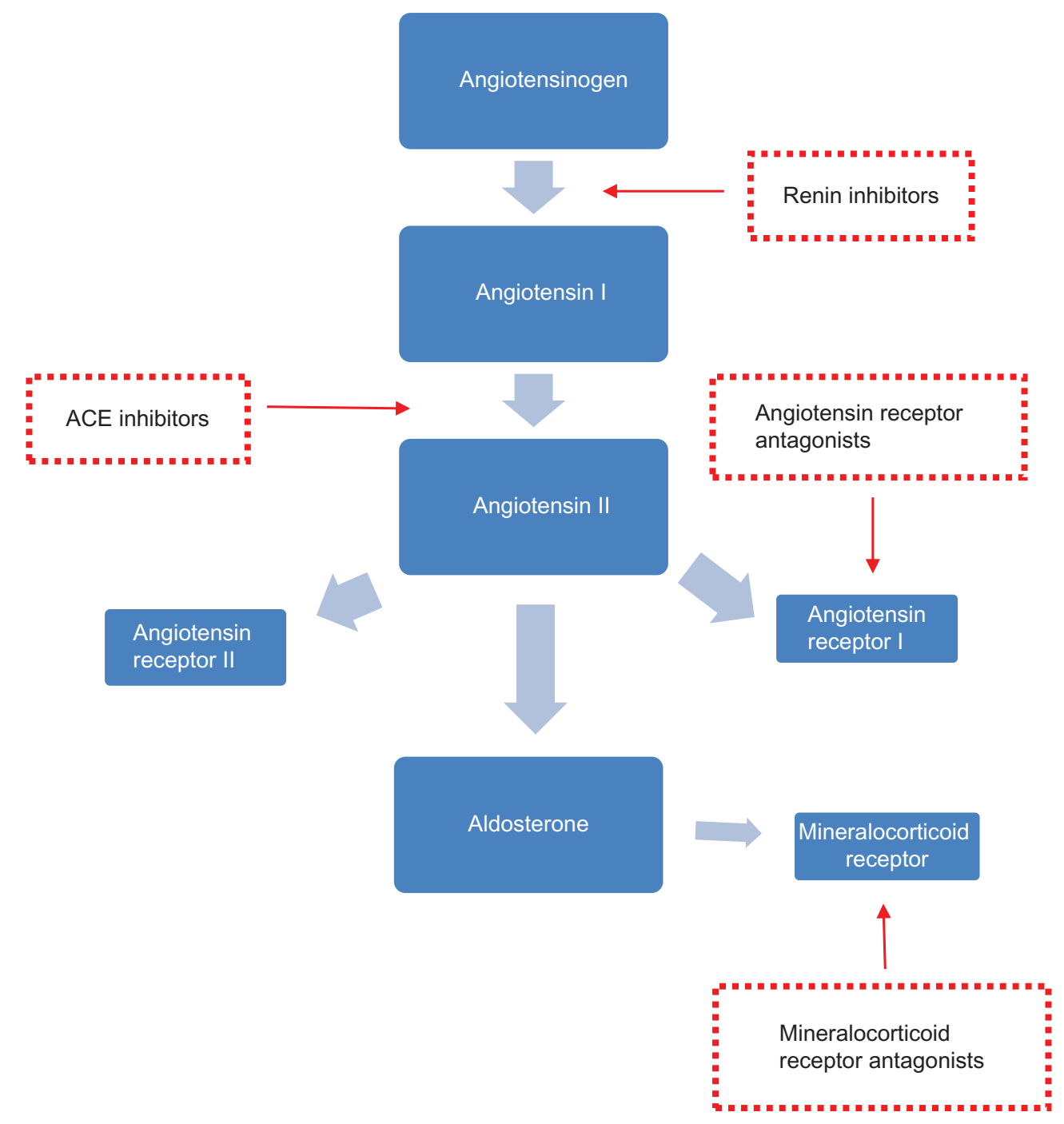

Figure I RAAS blocking agents and sites of action.

Abbreviations: ACE, angiotensin-converting-enzyme; RAAS, renin-angiotensin-aldosterone system.

effect was attributed to proteinuria reduction and limiting the deleterious effects of angiotensin II. ${ }^{98}$ Similar reductions in cardiovascular endpoints were shown in the diabetic subset (micro-HOPE). ${ }^{95}$ In another study, captopril reduced mortality in type 1 diabetic patients with nephropathy. ${ }^{94}$ Angiotensin receptor blockers have also been shown to improve cardiovascular morbidity and mortality. For example, in the LIFE study, losartan therapy reduced occurrence of the primary composite endpoint including death, myocardial infarction, and stroke in both diabetic and non-diabetic participants concomitant with reduction in albuminuria..$^{99,100}$ In addition, the Irbesartan Diabetic Nephropathy Trial demonstrated concomitant reductions in urinary protein excretion and cardiovascular endpoints in hypertensive type 2 diabetic participants; ${ }^{101}$ however, in the RENAAL trial, losartan therapy reduced hospitalizations for heart failure but did not show any significant effect on mortality rate. ${ }^{97}$

\section{Early intervention/dual RAAS blockade}

A number of studies have explored the risks and benefits of early initiation of RAAS blocking agents, or dual RAAS blockade. The ROADMAP study investigated early initiation of angiotensin receptor blockade in normoalbuminuric patients with type 2 diabetes and showed that this did indeed delay onset of microalbuminuria. This did not, however, translate into a beneficial impact on cardiovascular risk. ${ }^{102}$ The Ongoing Telmisartan Alone and in combination with Ramipril Global Endpoint Trial (ONTARGET) randomized participants with vascular disease or diabetes to receive telmisartan, ramipril, or a combination of both. Combination therapy was shown to offer greater reduction in proteinuria 
but this apparent benefit was offset by the lack of overall benefit in terms of cardiovascular outcomes and indeed a significant increase in adverse events, such as hypotensive symptoms and renal dysfunction. ${ }^{103,104}$ In adults with proteinuric CKD, the addition of aldosterone antagonists such as spironolactone or eplerenone to angiotensin-convertingenzyme (ACE)-inhibitor or angiotensin receptor blocker therapy has been shown to reduce protein excretion but to increase risk of adverse events such as hyperkalemia. ${ }^{105}$

\section{Direct renin inhibitors}

Direct renin inhibition offers potential to further optimize RAAS blockade by interfering with the first step in the pathway. Aliskiren is the first of this class to be licensed for treatment of hypertension. In comparative studies with other antihypertensives, aliskiren monotherapy appears to provide blood pressure reductions similar to those achieved with losartan or lisinopril ${ }^{106,107}$ as well as significant additive blood pressure reduction in combination with other agents. ${ }^{108,109}$ Several trials have shown that treatment with direct renin inhibitors such as Aliskiren in combination with other RAAS blocking agents have beneficial effects on endpoints including proteinuria and left ventricular hypertrophy in patients with diabetic nephropathy and non-diabetic CKD including transplant recipients or heart failure. ${ }^{110-113}$ The recent Aliskiren Trial in Type 2 Diabetes Using Cardiorenal Endpoints (ALTITUDE), however, was terminated early because of increased adverse outcomes including non-fatal stroke, hypotension, and hyperkalemia ${ }^{114}$ and further prospective studies are needed to confirm the safety and tolerability of these agents in CKD populations.

\section{Endothelin A blockade}

Although effective and the current mainstay of treatment of proteinuria, RAAS blockade does not always completely retard progression of proteinuria. ${ }^{115}$ Experimental data have demonstrated that endothelin A blockade can have favorable antiproteinuric and antifibrotic effects and these have been confirmed in studies in patients with diabetic nephropathy. ${ }^{116}$ Encouraging results have been published from a short term pilot study of Atrasentan documenting significant reduction in proteinuria in participants with diabetic nephropathy although studies on long term safety and efficacy are lacking and some negative effects have been demonstrated in patients with underlying cardiac disease. ${ }^{117}$

\section{Statins}

As well as being effective cholesterol-lowering agents with positive effects on cardiovascular outcomes, some have suggested that statins have an antiproteinuric effect. In a 2006 meta-analysis, statins were shown to reduce albuminuria in 13 out of 15 studies reviewed. The degree of reduction appeared to be greater in individuals who had higher baseline albumin excretion although there was marked variability in study quality. ${ }^{118} \mathrm{~A}$ subsequent meta-analysis including randomized controlled trials of statins in patients with CKD again showed a significant reduction in protein excretion as well as a reduction in cardiovascular events. ${ }^{119}$ It is unclear whether these perceived benefits are the result of lipid-lowering effects on endothelial function, reduction of inflammation and oxidative stress, or inhibitory effects on renal endothelin $1 .{ }^{120}$

\section{Non-pharmacological interventions}

As well as known carcinogenic effects, smoking has been shown to induce intimal proliferation and vascular hyaline thickening. ${ }^{121}$ As such, cigarette smoking is accepted as a major risk factor for cardiovascular disease. Similar histological changes have been described in the kidney. ${ }^{122}$ Multiple studies have shown an association between smoking and renal damage, at general population level as well as in patients with diabetes or hypertension. ${ }^{123}$ In epidemiological studies of otherwise healthy participants, the incidence of proteinuria has been positively associated with the number of cigarettes smoked per day, particularly in males ${ }^{124}$ and although no specific data exist to support cessation of smoking for reduction of proteinuria, smoking cessation is advised in KDOQI guidance on hypertension in CKD.

Obesity has been shown to be associated with proteinuria. ${ }^{125,126}$ Weight loss in combination with ACEinhibitor therapy have been shown to decrease levels of protein excretion in obese patients as well as proteinuria of other etiologies including diabetes. ${ }^{127}$ Moreover, a significant correlation between level of weight loss attained and reduction in proteinuria was demonstrated in the same study. ${ }^{127}$

Dietary protein restriction in patients with CKD remains a controversial issue due to the delicate balance between slowing progression of proteinuria and the importance of good nutritional status in chronic disease. Although limiting dietary protein intake to between 0.75 and $1.0 \mathrm{~g} / \mathrm{kg} /$ day is often recommended in the later stages of CKD, these diets can be unpalatable and compliance is variable. In addition, guidelines also recommend dietary sodium restriction to reduce cardiovascular risk in patients with CKD. ${ }^{9}$ Although no specific guidance exists on sodium restriction in patients with proteinuria, evidence suggests that dietary sodium restriction can enhance the effects of RAAS blocking agents in reducing 
urinary protein excretion. ${ }^{128,129}$ Most clinical guidelines suggest that a dietetic review for discussion of such modifications be considered for patients with advanced CKD although no specific guidance is available for the earlier stages of disease when GFR remains $>60 \mathrm{~mL} /$ minute $/ 1.73 \mathrm{~m}^{2}$.

Renal sympathetic innervation is another key component of the pathogenesis of hypertension through its effects on renin secretion, renal sodium absorption and glomerular filtration rate. ${ }^{130}$ In recent years, catheter-based renal sympathetic denervation has gained much attention as a potential tool in the management of resistant hypertension. Preliminary evidence suggests that this procedure can offer significant blood pressure reduction for resistant hypertensive patients with effects maintained at 24 months follow up, ${ }^{131,132}$ as well as beneficial effects on left ventricular mass and systolic function and arterial stiffness as measured by pulse wave velocity. ${ }^{133}$ In terms of renal hemodynamics, recent evidence suggests that renal denervation improved ultrasound renal resistive indices. This study also demonstrated that renal function as measured by creatinine and cystatin $\mathrm{C}$ was unchanged at 6 months follow up, suggesting that the procedure itself has no adverse effects on the kidneys at least in the short term. Urinary albumin excretion remained unchanged after denervation but the number of patients with micro or macroalbuminuria did fall, although it should be kept in mind that this was a small study. ${ }^{134}$ Whether this approach is equally safe and effective over longer term follow up in patients with eGFR less than $45 \mathrm{~mL} /$ minute remains to be seen.

\section{Conclusion}

The significant burden on health services posed by cardiovascular disease has prompted investigation of prognostic markers and therapeutic targets. There is a clear association between proteinuria and cardiovascular outcomes despite marked heterogeneity in the literature when considering the method of detection used and classification of degree of proteinuria. This association has been demonstrated both in disease population including hypertensives, diabetic patients, and those with CKD, as well as in otherwise healthy individuals. Proteinuria has evolved into a surrogate marker of cardiovascular risk and it seems intuitive that earlier detection and more aggressive intervention may serve to reduce risk in affected individuals. Several publications have considered the cost-effectiveness of population screening. In 2003 Boulware et al concluded that population screening for dipstick proteinuria was not cost-effective in terms of
CKD morbidity and mortality unless specifically targeted towards higher risk groups such as hypertensive or elderly patients and done at less frequent intervals. ${ }^{135}$ When considering prevention of cardiovascular events, an analysis of the PREVEND-IT study was more favourable. ${ }^{136}$ RAAS inhibition, together with control of additional cardiovascular risk factors, remains the mainstay of treatment for individuals with proteinuria. Studies of earlier and more aggressive intervention with two or more RAAS blocking agents have demonstrated reduction in proteinuria but this has not yet translated into reduction in hard clinical cardiovascular endpoints and these studies have also reported a greater degree of side effects and adverse events.

\section{Disclosure}

Work in our group is supported by grants from the European Commission "PRIORITY” (grant agreement 279277), "EUMASCARA" (grant agreement 278249) and "HOMAGE" (grant agreement 305507). The authors have no conflicts of interest to report.

\section{References}

1. Sarnak MJ, Levey AS, Schoolwerth AC, et al; American Heart Association Councils on Kidney in Cardiovascular Disease, High Blood Pressure Research, Clinical Cardiology, and Epidemiology and Prevention. Kidney disease as a risk factor for development of cardiovascular disease: a statement from the American Heart Association Councils on Kidney in Cardiovascular Disease, High Blood Pressure Research, Clinical Cardiology, and Epidemiology and Prevention. Circulation. 2003;108(17):2154-2169.

2. Agrawal V, Marinescu V, Agarwal M, McCullough PA. Cardiovascular implications of proteinuria: an indicator of chronic kidney disease. Nat Rev Cardiol. 2009;6(4):301-311.

3. Wagner DK, Harris T, Madans JH. Proteinuria as a biomarker: risk of subsequent morbidity and mortality. Environ Res. 1994;66(2):160-172.

4. Garg AX, Kiberd BA, Clark WF, Haynes RB, Clase CM. Albuminuria and renal insufficiency prevalence guides population screening: results from the NHANES III. Kidney Int. 2002;61(6):2165-2175.

5. Culleton BF, Larson MG, Parfrey PS, Kannel WB, Levy D. Proteinuria as a risk factor for cardiovascular disease and mortality in older people: a prospective study. Am J Med. 2000;109(1):1-8.

6. Segura J, Campo C, Ruilope LM. Proteinuria: an underappreciated risk factor in cardiovascular disease. Curr Cardiol Rep. 2002;4(6): 458-462.

7. Ljungman S, Wikstrand J, Hartford M, Berglund G. Urinary albumin excretion - a predictor of risk of cardiovascular disease. A prospective 10-year follow-up of middle-aged nondiabetic normal and hypertensive men. Am J Hypertens. 1996;9(8):770-778.

8. Kashif W, Siddiqi N, Dincer AP, Dincer HE, Hirsch S. Proteinuria: how to evaluate an important finding. Cleve Clin J Med. 2003;70(6): $535-537,541$.

9. National Kidney Foundation. KDQOI clinical practice guidelines for chronic kidney disease: evaluation, classification and stratification. Am J Kidney Dis. 2002;39(2 Supp1 1):s1-s266.

10. Go AS, Chertow GM, Fan D, McCulloch CE, Hsu CY. Chronic kidney disease and the risks of death, cardiovascular events, and hospitalization. N Engl J Med. 2004;351(13):1296-1305. 
11. Keith DS, Nichols GA, Gullion CM, Brown JB, Smith DH. Longitudinal follow-up and outcomes among a population with chronic kidney disease in a large managed care organization. Arch Intern Med. 2004;164(6):659-663.

12. Matsushita K, van der Velde M, Astor BC, et al; Chronic Kidney Disease Prognosis Consortium. Association of estimated glomerular filtration rate and albuminuria with all-cause and cardiovascular mortality in general population cohorts: a collaborative meta-analysis. Lancet. 2010; 375(9731):2073-2081.

13. Tonelli M, Wiebe N, Culleton B, et al. Chronic kidney disease and mortality risk: a systematic review. $J$ Am Soc Nephrol. 2006;17(7): 2034-2047.

14. Di Angelantonio E, Chowdhury R, Sarwar N, Aspelund T, Danesh J, Gudnason V. Chronic kidney disease and risk of major cardiovascular disease and non-vascular mortality: prospective population based cohort study. BMJ. 2010;341:c4986.

15. Herzog CA. Kidney disease in cardiology. Nephrol Dial Transplant. 2009;24(1):34-37.

16. Nagata M, Ninomiya T, Kiyohara Y, et al; EPOCH-JAPAN Research Group. Prediction of cardiovascular disease mortality by proteinuria and reduced kidney function: pooled analysis of 39,000 individuals from 7 cohort studies in Japan. Am J Epidemiol. 2013;178(1):1-11.

17. Hemmelgarn BR, Manns BJ, Lloyd A, et al; Alberta Kidney Disease Network. Relation between kidney function, proteinuria, and adverse outcomes. JAMA. 2010;303(5):423-429.

18. Kannel WB, Stampfer MJ, Castelli WP, Verter J. The prognostic significance of proteinuria: the Framingham study. Am Heart $J$. 1984;108(5):1347-1352.

19. Matsushita K, van der Velde M, Astor BC, et al; Chronic Kidney Disease Prognosis Consortium. Association of estimated glomerular filtration rate and albuminuria with all-cause and cardiovascular mortality in general population cohorts: a collaborative meta-analysis. Lancet. 2010;375(9731):2073-2081

20. Hillege HL, Fidler V, Diercks GF, et al; Prevention of Renal and Vascular End Stage Disease (PREVEND) Study Group. Urinary albumin excretion predicts cardiovascular and noncardiovascular mortality in general population. Circulation. 2002;106(14):1777-1782.

21. Irie F, Iso $\mathrm{H}$, Sairenchi $\mathrm{T}$, et al. The relationships of proteinuria, serum creatinine, glomerular filtration rate with cardiovascular disease mortality in Japanese general population. Kidney Int. 2006;69(7): 1264-1271.

22. Inoue T, Iseki K, Higashiuesato $\mathrm{Y}$, et al. Proteinuria as a significant determinant of hypertension in a normotensive screened cohort in Okinawa, Japan. Hypertens Res. 2006;29(9):687-693.

23. Wang Z, Hoy WE. Albuminuria and incident coronary heart disease in Australian Aboriginal people. Kidney Int. 2005;68(3):1289-1293.

24. Damsgaard EM, Frøland A, Jørgensen OD, Mogensen CE. Microalbuminuria as predictor of increased mortality in elderly people. BMJ. 1990;300(6720):297-300.

25. Bello AK, Hemmelgarn B, Lloyd A, et al; Alberta Kidney Disease Network. Associations among estimated glomerular filtration rate, proteinuria, and adverse cardiovascular outcomes. Clin J Am Soc Nephrol. 2011;6(6):1418-1426.

26. Perkovic V, Verdon C, Ninomiya T, et al. The relationship between proteinuria and coronary risk: a systematic review and meta-analysis. PLoS Med. 2008;5(10):e207.

27. Gerstein HC, Mann JF, Yi Q, et al; HOPE Study Investigators. Albuminuria and risk of cardiovascular events, death, and heart failure in diabetic and nondiabetic individuals. JAMA. 2001;286(4): 421-426.

28. Hillege HL, Janssen WM, Bak AA, et al; Prevend Study Group. Microalbuminuria is common, also in a nondiabetic, nonhypertensive population, and an independent indicator of cardiovascular risk factors and cardiovascular morbidity. J Intern Med. 2001;249(6): 519-526.
29. Wachtell K, Ibsen H, Olsen MH, et al. Albuminuria and cardiovascular risk in hypertensive patients with left ventricular hypertrophy: the LIFE study. Ann Intern Med. 2003;139(11):901-906.

30. Wachtell K, Olsen MH, Dahlöf B, et al. Microalbuminuria in hypertensive patients with electrocardiographic left ventricular hypertrophy: the LIFE study. $J$ Hypertens. 2002;20(3):405-412.

31. Lee M, Saver JL, Chang KH, Liao HW, Chang SC, Ovbiagele B. Impact of microalbuminuria on incident stroke: a meta-analysis. Stroke. 2010;41(11):2625-2631.

32. Ninomiya T, Perkovic V, Verdon C, et al. Proteinuria and stroke: a metaanalysis of cohort studies. Am J Kidney Dis. 2009;53(3):417-425.

33. Jensen JS, Feldt-Rasmussen B, Strandgaard S, Schroll M, BorchJohnsen K. Arterial hypertension, microalbuminuria, and risk of ischemic heart disease. Hypertension. 2000;35(4):898-903.

34. Nobakhthaghighi N, Kamgar M, Bekheirnia MR, McFann K, Estacio R, Schrier RW. Relationship between urinary albumin excretion and left ventricular mass with mortality in patients with type 2 diabetes. Clin $J$ Am Soc Nephrol. 2006;1(6):1187-1190.

35. Post WS, Blumenthal RS, Weiss JL, et al. Spot urinary albumin-creatinine ratio predicts left ventricular hypertrophy in young hypertensive African-American men. Am J Hypertens. 2000;13(11):1168-1172.

36. Dell'omo G, Giorgi D, Di Bello V, Mariani M, Pedrinelli R. Blood pressure independent association of microalbuminuria and left ventricular hypertrophy in hypertensive men. J Intern Med. 2003;254(1): 76-84.

37. Solomon SD, Lin J, Solomon CG, et al; Prevention of Events With ACE Inhibition (PEACE) Investigators. Influence of albuminuria on cardiovascular risk in patients with stable coronary artery disease. Circulation. 2007;116(23):2687-2693.

38. Jose P, Skali H, Anavekar N, et al. Increase in creatinine and cardiovascular risk in patients with systolic dysfunction after myocardial infarction. J Am Soc Nephrol. 2006;17(10):2886-2891.

39. Nazer B, Ray KK, Murphy SA, Gibson CM, Cannon CP. Urinary albumin concentration and long-term cardiovascular risk in acute coronary syndrome patients: a PROVE IT-TIMI 22 substudy. J Thromb Thrombolysis. 2013;36(3):233-239.

40. Mogensen CE. Microalbuminuria predicts clinical proteinuria and early mortality in maturity-onset diabetes. $N$ Engl J Med. 1984; 310(6):356-360.

41. Messent JW, Elliott TG, Hill RD, Jarrett RJ, Keen H, Viberti GC. Prognostic significance of microalbuminuria in insulin-dependent diabetes mellitus: a twenty-three year follow-up study. Kidney Int. 1992;41(4):836-839.

42. Borch-Johnsen K, Andersen PK, Deckert T. The effect of proteinuria on relative mortality in type 1 (insulin-dependent) diabetes mellitus. Diabetologia. 1985;28(8):590-596.

43. Lin CC, Chen CC, Kung PT, et al. Joint relationship between renal function and proteinuria on mortality of patients with type 2 diabetes: the Taichung Diabetes Study. Cardiovasc Diabetol. 2012;11:131.

44. Anavekar NS, Gans DJ, Berl T, et al. Predictors of cardiovascular events in patients with type 2 diabetic nephropathy and hypertension: a case for albuminuria. Kidney Int Suppl. 2004:S50-S55.

45. Dinneen SF, Gerstein HC. The association of microalbuminuria and mortality in non-insulin-dependent diabetes mellitus. A systematic overview of the literature. Arch Intern Med. 1997;157(13): $1413-1418$

46. Stadler M, Auinger M, Anderwald C, et al. Long-term mortality and incidence of renal dialysis and transplantation in type 1 diabetes mellitus. J Clin Endocrinol Metab. 2006;91(10):3814-3820.

47. de Jong PE, Gansevoort RT, Bakker SJ. Macroalbuminuria and microalbuminuria: do both predict renal and cardiovascular events with similar strength? J Nephrol. 2007;20(4):375-380.

48. Rossing P, Hougaard P, Borch-Johnsen K, Parving HH. Predictors of mortality in insulin dependent diabetes: 10 year observational follow up study. BMJ. 1996;313(7060):779-784. 
49. de Zeeuw D, Remuzzi G, Parving HH, et al. Albuminuria, a therapeutic target for cardiovascular protection in type 2 diabetic patients with nephropathy. Circulation. 2004;110(8):921-927.

50. Morrish NJ, Stevens LK, Fuller JH, Jarrett RJ, Keen H. Risk factors for macrovascular disease in diabetes mellitus: the London follow-up to the WHO Multinational Study of Vascular Disease in Diabetics. Diabetologia. 1991;34(8):590-594.

51. Escobedo J, Rana JS, Lombardero MS, et al; BARI 2D Study Group. Association between albuminuria and duration of diabetes and myocardial dysfunction and peripheral arterial disease among patients with stable coronary artery disease in the BARI 2D study. Mayo Clin Proc. 2010;85(1):41-46.

52. Liu JE, Robbins DC, Palmieri V, et al. Association of albuminuria with systolic and diastolic left ventricular dysfunction in type 2 diabetes: the Strong Heart Study. J Am Coll Cardiol. 2003;41(11): 2022-2028.

53. Vaur L, Gueret P, Lievre M, Chabaud S, Passa P; DIABHYCAR Study Group (type 2 DIABetes, Hypertension, CARdiovascular Events and Ramipril) study. Development of congestive heart failure in type 2 diabetic patients with microalbuminuria or proteinuria: observations from the DIABHYCAR (type 2 DIABetes, Hypertension, CArdiovascular Events and Ramipril) study. Diabetes Care. 2003;26(3):855-860.

54. Carr AA, Kowey PR, Devereux RB, et al. Hospitalizations for new heart failure among subjects with diabetes mellitus in the RENAAL and LIFE studies. Am J Cardiol. 2005;96(11):1530-1536.

55. MacDonald MR, Petrie MC, Hawkins NM, et al. Diabetes, left ventricular systolic dysfunction, and chronic heart failure. Eur Heart J. 2008;29(10):1224-1240.

56. On the horizon in heart failure. Lancet. 2011;378(9792):637.

57. van de Wal RM, Asselbergs FW, Plokker HW, et al. High prevalence of microalbuminuria in chronic heart failure patients. $J$ Card Fail. 2005;11(8):602-606.

58. Jackson CE, Solomon SD, Gerstein HC, et al; CHARM Investigators and Committees. Albuminuria in chronic heart failure: prevalence and prognostic importance. Lancet. 2009;374(9689):543-550.

59. Jackson CE, MacDonald MR, Petrie MC, et al; ALiskiren Observation of heart Failure Treatment (ALOFT) investigators. Associations of albuminuria in patients with chronic heart failure: findings in the ALiskiren Observation of heart Failure Treatment study. Eur J Heart Fail. 2011;13(7):746-754.

60. Smith DH, Thorp ML, Gurwitz JH, et al. Chronic kidney disease and outcomes in heart failure with preserved versus reduced ejection fraction: the Cardiovascular Research Network PRESERVE Study. Circ Cardiovasc Qual Outcomes. 2013;6(3):333-342.

61. Diercks GF, van Boven AJ, Hillege HL, et al. Microalbuminuria is independently associated with ischaemic electrocardiographic abnormalities in a large non-diabetic population. The PREVEND (Prevention of REnal and Vascular ENdstage Disease) study. Eur Heart J. 2000; 21(23):1922-1927.

62. Bigazzi R, Bianchi S, Nenci R, Baldari D, Baldari G, Campese VM. Increased thickness of the carotid artery in patients with essential hypertension and microalbuminuria. J Hum Hypertens. 1995;9(10): 827-833.

63. Mykkänen L, Zaccaro DJ, O'Leary DH, Howard G, Robbins DC, Haffner SM. Microalbuminuria and carotid artery intima-media thickness in nondiabetic and NIDDM subjects. The Insulin Resistance Atherosclerosis Study (IRAS). Stroke. 1997;28(9):1710-1716.

64. Kramer H, Jacobs DR, Bild D, et al. Urine albumin excretion and subclinical cardiovascular disease. The Multi-Ethnic Study of Atherosclerosis. Hypertension. 2005;46(1):38-43.

65. Upadhyay A, Hwang SJ, Mitchell GF, et al. Arterial stiffness in mildto-moderate CKD. J Am Soc Nephrol. 2009;20(9):2044-2053.

66. Deckert T, Feldt-Rasmussen B, Borch-Johnsen K, Jensen T, KofoedEnevoldsen A. Albuminuria reflects widespread vascular damage. The Steno hypothesis. Diabetologia. 1989;32(4):219-226.

67. Hellemons ME, Lambers Heerspink HJ, Gansevoort RT, de Zeeuw D, Bakker SJ. High-sensitivity troponin T predicts worsening of albuminuria in hypertension; results of a nested case-control study with confirmation in diabetes. J Hypertens. 2013;31(4):805-812.
68. Tsioufis C, Dimitriadis K, Chatzis D, et al. Relation of microalbuminuria to adiponectin and augmented C-reactive protein levels in men with essential hypertension. Am J Cardiol. 2005;96(7):946-951.

69. Yilmaz MI, Sonmez A, Saglam M, et al. ADMA levels correlate with proteinuria, secondary amyloidosis, and endothelial dysfunction. J Am Soc Nephrol. 2008;19(2):388-395.

70. Pedrinelli R, Giampietro O, Carmassi F, et al. Microalbuminuria and endothelial dysfunction in essential hypertension. Lancet. 1994; 344(8914):14-18.

71. Zhu X, Wu S, Dahut WL, Parikh CR. Risks of proteinuria and hypertension with bevacizumab, an antibody against vascular endothelial growth factor: systematic review and meta-analysis. Am J Kidney Dis. 2007;49(2):186-193.

72. Stehouwer CD, Gall MA, Twisk JW, Knudsen E, Emeis JJ, Parving HH. Increased urinary albumin excretion, endothelial dysfunction, and chronic low-grade inflammation in type 2 diabetes: progressive, interrelated, and independently associated with risk of death. Diabetes. 2002;51(4):1157-1165.

73. Knöbl P, Schernthaner G, Schnack C, et al. Thrombogenic factors are related to urinary albumin excretion rate in type 1 (insulin-dependent) and type 2 (non-insulin-dependent) diabetic patients. Diabetologia. 1993;36(10):1045-1050.

74. Hirano T, Kashiwazaki K, Moritomo Y, Nagano S, Adachi M. Albuminuria is directly associated with increased plasma PAI-1 and factor VII levels in NIDDM patients. Diabetes Res Clin Pract. 1997;36(1):11-18.

75. Mykkänen L, Zaccaro DJ, Wagenknecht LE, Robbins DC, Gabriel M, Haffner SM. Microalbuminuria is associated with insulin resistance in nondiabetic subjects: the insulin resistance atherosclerosis study. Diabetes. 1998;47(5):793-800.

76. Bianchi S, Bigazzi R, Valtriani C, et al. Elevated serum insulin levels in patients with essential hypertension and microalbuminuria. Hypertension. 1994;23(6 Pt 1):681-687.

77. Jee SH, Boulware LE, Guallar E, Suh I, Appel LJ, Miller ER. Direct, progressive association of cardiovascular risk factors with incident proteinuria: results from the Korea Medical Insurance Corporation (KMIC) study. Arch Intern Med. 2005;165(19):2299-2304.

78. Farasat SM, Valdes C, Shetty V, et al. Is longitudinal pulse pressure a better predictor of 24-hour urinary albumin excretion than other indices of blood pressure? Hypertension. 2010;55(2):415-421.

79. Bianchi S, Bigazzi R, Caiazza A, Campese VM. A controlled, prospective study of the effects of atorvastatin on proteinuria and progression of kidney disease. Am J Kidney Dis. 2003;41(3):565-570.

80. Ravid M, Brosh D, Ravid-Safran D, Levy Z, Rachmani R. Main risk factors for nephropathy in type 2 diabetes mellitus are plasma cholesterol levels, mean blood pressure, and hyperglycemia. Arch Intern Med. 1998;158(9):998-1004.

81. Ritz E, Viberti GC, Ruilope LM, et al. Determinants of urinary albumin excretion within the normal range in patients with type 2 diabetes: the Randomised Olmesartan and Diabetes Microalbuminuria Prevention (ROADMAP) study. Diabetologia. 2010;53(1):49-57.

82. Pinto-Sietsma SJ, Navis G, Janssen WM, de Zeeuw D, Gans RO, de Jong PE; PREVEND Study Group. A central body fat distribution is related to renal function impairment, even in lean subjects. $A m J$ Kidney Dis. 2003;41(4):733-741.

83. Fort J. Chronic renal failure: a cardiovascular risk factor. Kidney Int Suppl. 2005:S25-S29.

84. Redon J, Rovira E, Miralles A, Julve R, Pascual JM. Factors related to the occurrence of microalbuminuria during antihypertensive treatment in essential hypertension. Hypertension. 2002;39(3):794-798.

85. Palatini P, Mormino P, Dorigatti F, et al; HARVEST Study Group. Glomerular hyperfiltration predicts the development of microalbuminuria in stage 1 hypertension: the HARVEST. Kidney Int. 2006;70(3):578-584.

86. Parving HH, Lewis JB, Ravid M, Remuzzi G, Hunsicker LG; DEMAND investigators. Prevalence and risk factors for microalbuminuria in a referred cohort of type II diabetic patients: a global perspective. Kidney Int. 2006;69(11):2057-2063. 
87. Ibsen $\mathrm{H}$, Olsen $\mathrm{MH}$, Wachtell $\mathrm{K}$, et al. Does albuminuria predict cardiovascular outcomes on treatment with losartan versus atenolol in patients with diabetes, hypertension, and left ventricular hypertrophy? The LIFE study. Diabetes Care. 2006;29(3):595-600.

88. Asselbergs FW, Diercks GF, Hillege HL, et al; Prevention of Renal and Vascular Endstage Disease Intervention Trial (PREVEND IT) Investigators. Effects of fosinopril and pravastatin on cardiovascular events in subjects with microalbuminuria. Circulation. 2004;110(18): 2809-2816.

89. Peterson JC, Adler S, Burkart JM, et al. Blood pressure control, proteinuria, and the progression of renal disease. The Modification of Diet in Renal Disease Study. Ann Intern Med. 1995;123(10):754-762.

90. Tight blood pressure control and risk of macrovascular and microvascular complications in type 2 diabetes: UKPDS 38. UK Prospective Diabetes Study Group. BMJ. 1998;317(7160):703-713.

91. Kidney Disease: Improving Global Outcomes (KDIGO) CKD Work Group. KDIGO 2012 Clinical Practice Guideline for the Evaluation and Management of Chronic Kidney Disease. Kidney Int Suppl. 2013;3(1):1-150.

92. National Institute for Health and Clinical Excellence. NICE Clinical Guideline 66: The Management of Type 2 Diabetes. Available from: http://www.nice.org.uk/nicemedia/pdf/cg66niceguideline.pdf. Accessed November 27, 2013.

93. Randomised placebo-controlled trial of effect of ramipril on decline in glomerular filtration rate and risk of terminal renal failure in proteinuric, non-diabetic nephropathy. The GISEN Group (Gruppo Italiano di Studi Epidemiologici in Nefrologia). Lancet. 1997;349(9069): 1857-1863.

94. Lewis EJ, Hunsicker LG, Bain RP, Rohde RD. The effect of angiotensinconverting-enzyme inhibition on diabetic nephropathy. The Collaborative Study Group. N Engl J Med. 1993;329(20): 1456-1462.

95. Effects of ramipril on cardiovascular and microvascular outcomes in people with diabetes mellitus: results of the HOPE study and MICRO-HOPE substudy. Heart Outcomes Prevention Evaluation Study Investigators. Lancet. 2000;355(9200):253-259.

96. Lewis EJ, Hunsicker LG, Clarke WR, et al; Collaborative Study Group. Renoprotective effect of the angiotensin-receptor antagonist irbesartan in patients with nephropathy due to type 2 diabetes. $N$ Engl J Med. 2001;345(12):851-860.

97. Brenner BM, Cooper ME, de Zeeuw D, et al; RENAAL Study Investigators. Effects of losartan on renal and cardiovascular outcomes in patients with type 2 diabetes and nephropathy. $N$ Engl J Med. 2001;345(12):861-869.

98. Mann JF, Gerstein HC, Pogue J, Bosch J, Yusuf S. Renal insufficiency as a predictor of cardiovascular outcomes and the impact of ramipril: the HOPE randomized trial. Ann Intern Med. 2001;134(8): 629-636.

99. Dahlöf B, Devereux RB, Kjeldsen SE, et al; LIFE Study Group. Cardiovascular morbidity and mortality in the Losartan Intervention For Endpoint reduction in hypertension study (LIFE): a randomised trial against atenolol. Lancet. 2002;359(9311):995-1003.

100. Lindholm LH, Ibsen H, Dahlöf B, et al; LIFE Study Group. Cardiovascular morbidity and mortality in patients with diabetes in the Losartan Intervention For Endpoint reduction in hypertension study (LIFE): a randomised trial against atenolol. Lancet. 2002;359(9311): 1004-1010.

101. Parving HH, Lehnert H, Bröchner-Mortensen J, Gomis R, Andersen S, Arner P; Irbesartan in Patients with Type 2 Diabetes and Microalbuminuria Study Group. The effect of irbesartan on the development of diabetic nephropathy in patients with type 2 diabetes. N Engl J Med. 2001;345(12):870-878.

102. Haller H, Ito S, Izzo JL, et al; ROADMAP Trial Investigators. Olmesartan for the delay or prevention of microalbuminuria in type 2 diabetes. N Engl J Med. 2011;364(10):907-917.

103. ONTARGET Investigators, Yusuf S, Teo KK, Pogue J, Dyal L, Copland I, Schumacher H, Dagenais G, Sleight P, Anderson C. Telmisartan, ramipril, or both in patients at high risk for vascular events. N Engl J Med. 2008;358(15):1547-1559.
104. Mann J, Schmieder R, McQueen M, et al; ONTARGET investigators Renal outcomes with telimsartan, ramipril or both in people at high vascular risk (the ONTARGET study): a multicentre, randomised, double blind, controlled trial. Lancet. 2008;372(9638):547-553.

105. Navaneethan SD, Nigwekar SU, Sehgal AR, Strippoli GF. Aldosterone antagonists for preventing the progression of chronic kidney disease: a systematic review and meta-analysis. Clin J Am Soc Nephrol. 2009;4(3):542-551.

106. Stanton A, Jensen C, Nussberger J, O’Brien E. Blood pressure lowering in essential hypertension with an oral renin inhibitor, aliskiren Hypertension. 2003;42(6):1137-1143.

107. Strasser RH, Puig JG, Farsang C, Croket M, Li J, van Ingen H. A comparison of the tolerability of the direct renin inhibitor aliskiren and lisinopril in patients with severe hypertension. J Hum Hypertens. 2007;21(10):780-787.

108. Villamil A, Chrysant SG, Calhoun D, et al. Renin inhibition with aliskiren provides additive antihypertensive efficacy when used in combination with hydrochlorothiazide. J Hypertens. 2007;25(1): 217-226.

109. Uresin Y, Taylor AA, Kilo C, et al. Efficacy and safety of the direct renin inhibitor aliskiren and ramipril alone or in combination in patients with diabetes and hypertension. J Renin Angiotensin Aldosterone Syst. 2007;8(4):190-198.

110. Parving HH, Persson F, Lewis JB, Lewis EJ, Hollenberg NK; AVOID Study Investigators. Aliskiren combined with losartan in type 2 diabetes and nephropathy. N Engl J Med. 2008;358(23):2433-2446.

111. Oparil S, Yarows SA, Patel S, Fang H, Zhang J, Satlin A. Efficacy and safety of combined use of aliskiren and valsartan in patients with hypertension: a randomised, double-blind trial. Lancet 2007;370(9583):221-229.

112. Li S, Chen Y, Yang W, et al. Effects of add-on direct renin inhibitor aliskiren in patients with non-diabetes related chronic kidney disease. BMC Nephrol. 2012;13:89.

113. López V, Martin M, Cobelo C, et al. Renin-angiotensin system dual blockade using angiotensin receptor plus aliskiren decreases severe proteinuria in kidney transplant recipients. Transplant Proc. 2010;42(8):2883-2885.

114. Parving $\mathrm{HH}$, Brenner BM, McMurray JJ, et al; ALTITUDE Investigators. Cardiorenal end points in a trial of aliskiren for type 2 diabetes. N Engl J Med. 2012;367(23):2204-2213.

115. Shiigai T, Shichiri M. Late escape from the antiproteinuric effect of ace inhibitors in nondiabetic renal disease. Am J Kidney Dis. 2001;37(3):477-483.

116. Wenzel RR, Littke T, Kuranoff S, et al; SPP301 (Avosentan) Endothelin Antagonist Evaluation in Diabetic Nephropathy Study Investigators. Avosentan reduces albumin excretion in diabetics with macroalbuminuria. J Am Soc Nephrol. 2009;20(3):655-664.

117. Kohan DE, Pritchett Y, Molitch M, et al. Addition of atrasentan to renin-angiotensin system blockade reduces albuminuria in diabetic nephropathy. J Am Soc Nephrol. 2011;22(4):763-772.

118. Douglas K, O’Malley PG, Jackson JL. Meta-analysis: the effect of statins on albuminuria. Ann Intern Med. 2006;145(2):117-124.

119. Strippoli GF, Navaneethan SD, Johnson DW, et al. Effects of statins in patients with chronic kidney disease: meta-analysis and meta-regression of randomised controlled trials. BMJ. 2008;336(7645):645-651.

120. Lee TM, Su SF, Tsai CH. Effect of pravastatin on proteinuria in patients with well-controlled hypertension. Hypertension. 2002;40(1):67-73.

121. Remuzzi G. Cigarette smoking and renal function impairment. Am J Kidney Dis. 1999;33(4):807-813.

122. Oberai B, Adams CW, High OB. Myocardial and renal arteriolar thickening in cigarette smokers. Atherosclerosis. 1984;52(2):185-190.

123. Orth SR, Hallan SI. Smoking: a risk factor for progression of chronic kidney disease and for cardiovascular morbidity and mortality in renal patients - absence of evidence or evidence of absence? Clin J Am Soc Nephrol. 2008;3(1):226-236.

124. Tozawa M, Iseki K, Iseki C, Oshiro S, Ikemiya Y, Takishita S. Influence of smoking and obesity on the development of proteinuria. Kidney Int. 2002;62(3):956-962. 
125. Morales E, Huerta A, Gutiérrez E, Gutiérrez Solís E, Segura J, Praga M. [The antiproteinuric effect of the blockage of the reninangiotensin-aldosterone system (RAAS) in obese patients. Which treatment option is the most effective?]. Nefrologia. 2009;29(5): 421-429. Spanish.

126. Praga M. Therapeutic measures in proteinuric nephropathy. Kidney Int Suppl. 2005:S137-S141.

127. Praga M, Hernández E, Andrés A, León M, Ruilope LM, Rodicio JL. Effects of body-weight loss and captopril treatment on proteinuria associated with obesity. Nephron. 1995;70(1):35-41.

128. Slagman MC, Waanders F, Hemmelder MH, et al; HOlland NEphrology STudy Group. Moderate dietary sodium restriction added to angiotensin converting enzyme inhibition compared with dual blockade in lowering proteinuria and blood pressure: randomised controlled trial. BMJ. 2011;343:d4366.

129. Vegter S, Perna A, Postma MJ, Navis G, Remuzzi G, Ruggenenti P. Sodium intake, ACE inhibition, and progression to ESRD. J Am Soc Nephrol. 2012;23(1):165-173.

130. Gulati V, White WB. Review of the state of renal nerve ablation for patients with severe and resistant hypertension. J Am Soc Hypertens. 2013.

131. Esler MD, Krum H, Sobotka PA, Schlaich MP, Schmieder RE, Böhm M; Symplicity HTN-2 Investigators. Renal sympathetic denervation in patients with treatment-resistant hypertension (The Symplicity HTN-2 Trial): a randomised controlled trial. Lancet. 2010;376(9756): 1903-1909.
132. Symplicity HTN-1 Investigators. Catheter-based renal sympathetic denervation for resistant hypertension: durability of blood pressure reduction out to 24 months. Hypertension. 2011;57(5):911-917.

133. Brandt MC, Mahfoud F, Reda S, et al. Renal sympathetic denervation reduces left ventricular hypertrophy and improves cardiac function in patients with resistant hypertension. J Am Coll Cardiol. 2012;59(10):901-909

134. Mahfoud F, Cremers B, Janker J, et al. Renal hemodynamics and renal function after catheter-based renal sympathetic denervation in patients with resistant hypertension. Hypertension. 2012;60(2): 419-424.

135. Boulware LE, Jaar BG, Tarver-Carr ME, Brancati FL, Powe NR. Screening for proteinuria in US adults: a cost-effectiveness analysis. JAMA. 2003;290(23):3101-3114.

136. Atthobari J, Asselbergs FW, Boersma C, et al; PREVEND IT Study Group. Cost-effectiveness of screening for albuminuria with subsequent fosinopril treatment to prevent cardiovascular events: A pharmacoeconomic analysis linked to the prevention of renal and vascular endstage disease (PREVEND) study and the prevention of renal and vascular endstage disease intervention trial (PREVEND IT). Clin Ther. 2006;28(3):432-444.

\section{Publish your work in this journal}

The International Journal of Nephrology and Renovascular Disease is an international, peer-reviewed open-access journal focusing on the pathophysiology of the kidney and vascular supply. Epidemiology, screening, diagnosis, and treatment interventions are covered as well as basic science, biochemical and immunological studies. The journal welcomes original research, clinical studies, reviews \& evaluations, expert opinion and commentary, case reports and extended reports. The manuscript management system is completely online and includes a very quick and fair peerreview system, which is all easy to use. Visit http://www.dovepress.com/ testimonials.php to read real quotes from published authors. 